Article

\title{
Biologically Based Methods for Pest Management in Agriculture under Changing Climates: Challenges and Future Directions
}

\author{
Frank Chidawanyika ${ }^{1, \dagger}$, Pride Mudavanhu ${ }^{2}$ and Casper Nyamukondiwa ${ }^{3, *}$
}

1 Global Change and Sustainability Research Institute, School of Animal, Plant and Environmental

Sciences, Faculty of Science, University of the Witwatersrand, Private Bag 3, Wits 2050,

Johannesburg, South Africa; E-Mail: fchidawanyika@icipe.org

2 Department of Conservation Ecology and Entomology, Faculty of AgriSciences, Stellenbosch University, Private Bag X1, Matieland 7602, South Africa; E-Mail: mudavanhu@sun.ac.za

3 Department of Earth and Environmental Sciences, Faculty of Science, Botswana International University of Science and Technology (BIUST). Private Bag BO 041 Bontleng, Gaborone, Botswana

$\dagger$ Current address: International Centre of Insect Physiology and Ecology (ICIPE), Habitat Management Programme, Plant Health Division, P.O. Box 30, Mbita Point Research Station, Mbita Point, Kenya

* Author to whom correspondence should be addressed;

E-Mail: nyamukondiwac@biust.ac.bw; Tel.: +267-392-6909; Fax: +267-392-6904.

Received: 13 August 2012; in revised form: 8 October 2012 / Accepted: 12 October 2012 /

Published: 9 November 2012

\begin{abstract}
The current changes in global climatic regimes present a significant societal challenge, affecting in all likelihood insect physiology, biochemistry, biogeography and population dynamics. With the increasing resistance of many insect pest species to chemical insecticides and an increasing organic food market, pest control strategies are slowly shifting towards more sustainable, ecologically sound and economically viable options. Biologically based pest management strategies present such opportunities through predation or parasitism of pests and plant direct or indirect defense mechanisms that can all be important components of sustainable integrated pest management programs. Inevitably, the efficacy of biological control systems is highly dependent on natural enemy-prey interactions, which will likely be modified by changing climates. Therefore, knowledge of how insect pests and their natural enemies respond to climate variation is of fundamental importance in understanding biological insect pest management under global
\end{abstract}


climate change. Here, we discuss biological control, its challenges under climate change scenarios and how increased global temperatures will require adaptive management strategies to cope with changing status of insects and their natural enemies.

Keywords: climate change; integrated pest management; insect population dynamics

\section{Introduction}

Anthropogenic climate change has the potential to significantly influence the biology of all organisms, but particularly ectotherms [1-3]; hence the evidence for a shift in ectotherm distribution in response to climate change [4,5]. While climate change is often associated with global mean annual temperature increases [6], likely favoring winter survival of insect pests, it is also coupled with increasing frequency and severity of extreme temperatures [7-12] that may modify predictions of insect population dynamics [13-15]. Short-term thermal fluctuations can be particularly stressful to small insects because their body temperatures are typically in equilibrium with ambient temperatures [16-18]. Hence, insects must be able to cope physiologically or compensate behaviorally with such changes in ambient temperature, both on spatial and temporal scales $[15,19,20]$. Physiologically, insects can adjust thermal tolerance over the short term, a phenomenon typically termed 'hardening' [21,22]. Over the longer term, thermal tolerance may be altered through acclimation in the laboratory or acclimatization in the field, and generally is a response to changes in environmental mean temperatures with e.g., season [23,24]. Hardening typically yields reversible physiological changes while acclimation and acclimatization can produce either reversible or irreversible physiological changes depending on the trait or whether developmental or maternal stages were exposed to temperature variation [22,24-26]. Martinat (1987) emphasized the importance of incorporating short-term undesirable weather transients (e.g., cold spells) in determining insect population dynamics [27]. Nevertheless, previous studies suggest considerable complexity when attempting to predict effects of transient weather patterns on insects' physiology or life-history traits [28-30].

Biological control is a method of controlling pests that relies on predation, parasitism, herbivory and other natural mechanisms and can be an important component of integrated pest management (IPM) programs [31]. However, the efficacy of biological control using natural enemies depends on a complex but delicate relationship between natural enemies and their insect pest hosts whose balance can be offset by a changing climate. Environmental factors (e.g., temperature) directly affects the survival, development, reproduction and dispersal of pest insects and thus their potential biogeography and biotic potential [32,33]. It is well known that temperature fluctuations are the major factors affecting insect biology, activity and distribution of natural enemies in agro-ecosystems [34,35]. Moreover, several studies have indicated climate change affects several life history parameters e.g., generation time, fecundity, sex ratios and lifespan of parasitoids and their natural enemies [36,37]. Similarly, temperature extremes may reduce insect survival, reduce fecundity and retard natural enemies' development [38]. 
Several studies have documented the likely effects of a changing climate on insect pest-natural enemies' interactions [35,39-41]. Similarly, by assessing physiological traits of thermal tolerance and water balance, [42] it was shown that global climate change may affect the phenology of Paractora dreuxi Seguy (Diptera: Helcomyzidae). This review aims at examining the likely effects of climate change on insect biological control and how increased global temperatures will require adaptive management strategies to cope with changing status of insects and their natural enemies. We discuss how changes in global climate factors such as temperature increase will impact on [1] insect-natural enemy-host plant interactions, [2] insect/plant diversity [3] population growth/abundance [4] effectiveness of crop protection technologies, with special emphasis to biological control using natural enemies. This information has critical implications for sustainable pest management and food security, especially for developing countries in Africa, where food security is an urgent challenge [43].

\section{Biologically-Based Pest Control Methods}

Reducing public health and environmental risks associated with chemical pesticide use is of growing concern in developed and developing countries [44]. This has motivated the call for the adoption of biologically based IPM systems, an essential step towards reducing risks associated with the use of highly toxic pesticides [44].

Biological control can be classified into three basic categories namely conservation, classical and augmentation [45,46]. First, conservation biological control (CBC) involves the deliberate human practice aimed at promoting the survival and activity of natural enemies at the expense of pest populations [47]. For example, ecological strips consisting of selected non-crop plants can be deliberately created to provide food sources and overwintering shelters as well as protect local natural enemies from pesticide disturbances thereby enhancing $\mathrm{CBC}$ as successfully shown in cereals, cabbages, and fruit orchards $[48,49]$.

Plant indirect defense mechanisms which rely on volatiles that call for natural enemies after pest damage, herbivore induced plant volatiles (HIPVs), have also been exploited to increase the activity of parasitoids in CBC systems [49,50]. In New Zealand and Australia the "attract and reward" is another form of the CBC approach where the use of HIPVs is combined with measures that increase key resources needed by natural enemies such as flowering plants in the commercial crop [50]. More recently, another form of $\mathrm{CBC}$ which combines stimulo-deterrent diversion tactics and conservation of parasitoids, through careful habitat manipulation has been shown to be effective against stem borers on sorghum Sorghum bicolor L. (Moench) and maize Zea mays L. [51]. Habitat manipulation has also been used to increase nectar availability, which increases the fecundity and longevity of some parasitoids [52-54], thereby increasing the efficacy of the program. For example, flowers are planted into commercial brassicaceous crops to enhance suppression of the diamondback moth, Plutella xylostella $(\mathrm{L}$.$) by its natural enemies [55].$

Second, classical biological control (BC) involves collection of natural enemies from their area of origin and releasing them in the new area where their host was introduced accidentally $[46,56]$. This is of particular importance when the introduced pest species has no known alternative parasitoids indigenous to the area. However, the efficacy of a classical biological will depend on the newly 
released parasitoids to successfully establish populations that can compete in the new environment. For example in the USA, the alien yellow starthistle Centaurea solstitialis [L] has been successfuly controlled by insect natural enemies such as Bangasternus orientalis [Carpiomont], Eusternopus villosus (Boheman), Urophora sirunaseva (Hering) and Chaetorellia succinea (Costa) that attack the seed head [57].

Last, augmentative biological control $(\mathrm{ABC})$ is the periodic release of large numbers of mass-reared natural enemies with the aim of supplementing natural enemy populations or flooding (i.e., inundating) pest populations with natural enemies [46,58]. It is commercially deployed in various cropping systems worldwide and two forms of $\mathrm{ABC}$ are distinguished namely the inundative approach and the seasonal inoculative method [46,59]. In the inundative release method, the BC agent is collected, mass-reared and released periodically in large numbers as for example a biotic insecticide to achieve immediate pest control in crops where viable breeding populations of the natural enemy are not possible [46]. This approach has been successfully applied in sugarcane for control of the sugarcane borer Diatraea saccharalis (F) in Latin America [60]. Other examples include the inundative release of common green lacewings Chrysoperla carnea (Stephens) to suppress Erythroneura variabilis (Beamer) and E. elegantula (Osborn) in vineyards [61]; and the release of Trichogramma spp for control of lepidopteran pests in vegetables, corn, rice, other cereals and cotton in Russia, China, SE Asia, Mexico and South America [62].

The seasonal inoculative approach differs from inundative method in that it is deployed in short-term crops, the production season of which is not longer than one year and where multiple pest generations occur [46]. The aim of the method is to obtain both immediate pest control as well as a build-up of the biological control agent population over the entire duration of the same production season [46]. Examples of the successful deployment of this technique include the release of Trissolcus basalis (Wollaston) for the control of Nezara viridula (L) in Brazil [63]; biological control of soybean stink bugs by inoculative releases of T. basalis [64]; control of the citrus blackfly, Aleurocanthus woglumi (Ashby) by inoculative releases of Eretmocerus serius (Silvestri) and Amitus hesperidium (Silvestri) in Cuba, Costa Rica, Mexico and Panama [46]; and the inoculation with Metarhizium flavoviride (Gams and Rozyspal) or Verticillium lecanii (Zimmerman) for the control of locusts Schistocerca gregaria (Forskal) [65] and grasshoppers [66].

\section{Challenges in Biologically-Based Pest Management in Relation to Climate Change}

Alterations in physiology and population dynamics, as a result of climate change, will bring new arrangements to levels of biological organization and ultimately ecological interactions in various species. In most geographic locations, shifts in climates may result in novel environmental conditions which are not only likely able to reduce the fitness but also deplete the quality and quantity of resources (e.g., food habitat) available for arthropod communities thereby threatening their existence in those areas. To counter this, arthropod populations facing unfavorable conditions may respond through either physiological or behavioral compensation [20,67], at both individual and population level, to better compete in the new environment; or they may migrate to new and favorable locations [68]. However, due to differences in the capacity to respond to various abiotic stressors and resource availability, fitness levels and dominance of various individual populations, they will be threatened, 
resulting in new species composition per locality, possibly dominated by the most adaptive ones [30]. Moreover, such modifications by living organisms, for better survival in life threatening environmental conditions, have already been hypothesized to pose new problems to them [69].

In turn, the resultant failure to successfully compete in the stressful conditions may lead to different species composition in both pests and their natural enemies. For agriculture, such changes are of importance as they create new structures in original pest abundance, emergence of formerly secondary to primary pests [32], colonization of new areas which were previously unfavorable $[40,68]$ and more importantly the modifications of habitats [67,70-72], which may lead to reduction in numbers of natural enemies and parasitoids in the agro-ecosystem. Consequently, the changes may result in reduction in the efficacy of biological control due to alterations in the predator-prey relationships or lack thereof. In this section, an overview of challenges in biological control as a result of climate-induced changes in pest or parasitoid biology and general habitat modifications is discussed.

\subsection{Habitat Fragmentation and Natural Enemy Diversity or Abundance}

It is widely known that crop surroundings play a crucial role in the conservation of natural enemies and parasitoids [49,73-75]. However, in most agro-ecosystems, much attention is paid to the crop (e.g., planting, irrigation fertilization) as compared with the peripheral environment. Such an approach has not only ensured perpetual optimal crop growth, but dependable hosts for pests as well. Through elaborate efforts that ensure crop growth and survival, insect pest herbivory has been indirectly guaranteed. However, this is contrary to the micro environment faced by natural enemies dwelling in the periphery where the natural habitats may not be receiving similar attention resulting in their numbers being reduced.

One consequence of changing climates may be habitat fragmentation of living organisms [1,76,77]. Thus, losses in suitable habitats will threaten the biodiversity and mere existence of organisms [78] including natural enemies or predators and parasitoids important for pest control in agro-ecosystems [75]. Consequently, the reduction or extinction of natural enemy populations will permit a pest build up, if unchecked, or over-reliance on alternative tactics for pest control which may be unsustainable, environmentally unfriendly and deplored by the consumers.

\subsection{Insect Biology and Physiology in Relation to Environmental Change}

Temperature affects a range of biochemical and physiological processes and, along with water availability, is probably the major environmental factor affecting insect population dynamics at either the individual or population level $[20,79,80]$. At individual level, it has already been shown that factors such as temperature play a key role in determining insect fitness [81], field performance [82,83] and survival [84]. However, because of variability in response to thermal stress, for instance, which might be introduced by age, gender, ontogeny [85] and the species in question, mismatches in development and activity between pests and parasitoids may occur with cascading effects on the efficacy of biological control programs. Use of mass-reared parasitoids in augmentative efforts may be a challenge as well since the insects being introduced into novel environments, which might be stressful, may perform poorly [86]. Hence, in scenarios where pests perform better than their corresponding indigenous parasitoids under stress, the efficacy of a biological program will be dramatically reduced. 
However, some parasitoid species in the wild may benefit from rising winter temperatures. As discussed by Hance et al. (2007 and references therein), exposure to cold temperature in juvenile parasitoids results in reduced longevity of the adults [39]. Furthermore, cold exposure of adult parasitoids in the family Scelionidae reduces their longevity even after returning to optimal or warmer temperatures [39,87]. Low temperatures during development are also known to cause deformations and low fecundity in parasitoids. Basing on these limitations posed by low temperatures, a rise in winter temperatures may become beneficial to biologically-based pest management strategies for these specific parasitoid species, through improvements in their fecundity, development and longevity. At a population level, rising temperatures result in reduced generation time, rapid population growth and sometimes increased geographical ranges depending on resource availability $[15,20]$. However, such a positive correlation in temperature and population increase in pests is not uniform across different species even when facing similar conditions. This results in the asynchrony of life cycles of pests and parasitoids (or general reduction in populations of parasitoids required to effectively suppress pest populations. Such an asynchrony will create a temporal shortage or extinction of food resources for parasitoids whilst crop pest phenology is in line with the crop cycle. This consequently exerts pressure on the cropping system, especially in the cases of specialist parasitoids [88].

Furthermore, some pests may increase their invasion potential in relation to their ability to deal with changing climates either through phenotypic plasticity or variation in basal tolerance [89-92]. A classic example is the invasive maize stemborer Chilo partellus (Swinhoe), which was first introduced to Africa accidentally in Malawi but managed to establish itself in several African countries, becoming more destructive than the indigenous species in some instances [93]. Whilst the first introduction of $C$. partellus into Africa may have not been due to climate change, it has become apparent that its further establishment in several African regions follows a distinct pattern, which may be partly influenced by both climate and altitude [94]. Such pest dynamics increase pressure on the already-strained predator and parasitoid populations.

\subsection{Chemical Ecology and Tritrophic Interactions in Agroecosystems}

Climate induced changes in plant factors will affect quality and quantity of resources available for the insects resulting in variable direct and indirect consequences on the development times, size and fitness of both pests and parasitoids [95]. This may thus offset predation and parasitism [95], which sometimes reduces the efficacy of biological control programs.

Perhaps another dimension of plant physiology which is likely to be modified, due to climate change, with a resultant impact on biological control is their secondary metabolism with a resultant impact on indirect defense mechanisms. It has already been shown that some plant species emit specific volatiles in response to elicitors in the saliva or secretions (during oviposition) of particular foraging herbivores, which call for natural enemies and parasitoids of the herbivores in question [96]. Other plant species, when attacked, have also been shown to emit volatile compounds which warn neighboring plants to prime their defense in advance in a phenomenon referred to as 'eavesdropping' [97]. Such volatiles have since been generally called herbivore induced plant volatiles (HIPVs) [97]. The HIPVs have been regarded as having evolutionary significance in that their production is only switched on when needed as opposed to constitutive mechanisms, which are always 
switched on. The latter may hence be 'wasteful' in terms of plant resource investment. However, recent studies have shown that plants undergoing abiotic stress respond by production of volatile isoprenoid compounds, perhaps, to avoid oxidative damage as a result of accumulation of reactive oxygen species in plants undergoing abiotic stress [98]. Isoprene compounds have since been shown to have the capacity to repel other specialist parasitoids, such as Diadegma semiclausum Hellen [99,100], and to influence herbivore feeding decisions [101]. It is therefore clear that isoprene production, as a result of abiotic stress, may influence plant-insect interactions in different agro-ecosystems. However, little is known of how the plants will prioritize their defense, in terms of volatile emission, when faced with biotic and multiple abiotic stressors associated with climate change.

For biological control, changes in volatile composition important for defense may result in failure for parasitoids to locate their host as some may require specific volatile blends in order to perform the desired functions [102]. Moreover, it has been shown that environmental stressors such as temperature impact on fitness, olfactory perception [103] and ultimately the ability to of the insects to track their hosts [95]. Therefore, if such changes occur in the parasitoids, biological control programs using natural enemies will be rendered less effective.

\subsection{Complexity in the Outcome of Climate Change Impacts on Natural Enemy Abundance and} Population Dynamics

While it has increasingly become clear that the climate is changing [6], an accurate prediction of the consequent effects on species distribution remains a daunting task. In most ecosystems, baseline species distribution, before any change in climates, is determined by a host of interactive factors between abiotic and biotic factors of the species in question. However, bioclimatic models used to predict future species prediction have often omitted or failed to account for all of the important factors resulting in them being questionable $[104,105]$. In these models, behavioral, dispersal mechanisms and inter-specific interactions, which can be made by living organisms in changing climates, have often been neglected [106,107] or assumptions which bring uncertainties to the models have often been used [105]. Such lack of availability of reliable tools for prediction are a challenge to farmers, in particular, those who are currently or plan to use biological control as their main insect pest control tactic. Availability of reliable tools will not only boost the confidence in users of the model, but also avert catastrophes in pest management due to over-reliance on flawed models.

Apart from bioclimatic models, resource constraints and challenges in experimental design have made empirical elucidation of the ecologically relevant behavioral and biological responses to climate change difficult. As a result, most inferences on the outcome of climate change are made from ecophysiological studies based on a single as opposed to multiple abiotic factors acting on different species. This is done despite increasing evidence of the differences in vulnerability or responses exhibited by some organisms when facing multiple as opposed to single stressors [108]. Possibly, through cross-tolerance [109] or additive effects of different stressors, such differences arise and may be species specific. It can therefore sometimes be misleading to rely on the inferences from the single-factor approach even though they serve as an important baseline indicator for individual physiological limits to stress tolerance. Such challenges bring new complications to farmers who are in 
principal, supposed to rely on accurate data and predictions in order to carry adequate planning and implementation of their crop protection strategies.

\section{Future Directions}

\subsection{Environmental Stress Biology, Evolutionary Resilience and Ecologically Relevant Measures for Organism Response to Changes in Climates}

Insect population dynamics can be strongly influenced by adaptive behaviors and traits [110]. Furthermore, insects/natural enemy extinction events, colonization rates and demographic rates are influenced by organisms' adaptation in habitat selection, life history traits, niche breadth and dispersal behavior [111]. Recent studies suggest that in most cases, adaptive traits (e.g., thermal tolerance), significantly affect demographic dynamics and hence shape species distributions and population dynamics under a changing climate $[86,112,113]$. Similarly, in insects, low genetic variation in thermal adaptation can limit population growth and increase extinction risks in organisms living closer to their critical thermal limits $[109,114]$. However, although it is generally accepted that climate is changing, mitigating and coping with these effects remains an unresolved challenge $[115,116]$. In order to maintain or even improve biological control using natural enemies in a changing climate, several adaptive management strategies need to be implemented to cope with the changing status of insects and their natural enemies.

First and foremost, experimental protocols investigating the likely probable effects of climate change on insect-natural enemy interactions needs to be highly accurate. Although it has been documented that laboratory determined physiological traits (e.g., thermal tolerance) closely approximates their ability to cope with the stress under natural environments and are good indices of species fitness facing climate change [1], in most cases, there are ranging debates over the ecological relevance of experimental protocols used. For example, in thermal biology, previous studies have indicated that the methodological approach employed to determine an insect's thermal tolerance can affect the types of insights that can be gained, and ecological relevance, of these thermal limits $[20,117]$. We therefore suggest that experimental protocols predicting climate change effects on insect population abundance should incorporate ecologically relevant measures of fitness traits (e.g., temperature tolerance) that are likely to occur in the species' natural environment [118].

Moreover, forecasting efforts for insects' responses to climate change has almost exclusively focused on the variation in mean temperatures $[1,119]$. However, it is expected that the magnitude and severity of temperature variances and extremes may also increase under future scenarios [7,12] with concomitant reduction in ectotherm fitness $[113,120]$. From a functional perspective, how changes in means and variances of temperature might affect the basal, phenotypic plasticity of temperature tolerance as well as life-history traits of ectotherms, remain poorly elucidated but are critical for predicting physiological responses in the wild [30,121]. We suggest that detailed analyses of changes in both means and variability of temperature for both pests and their natural enemies are a critical component of accurate forecasting of insect/natural enemy population-level responses to climate change. Furthermore, some other environmental stressors other than temperature may also impact synergistically or antagonistically on ectotherm fitness in a changing climate [118]. We therefore 
suggest that experimental protocols investigating ectotherm fitness in a changing climate should also incorporate other factors to evaluate possible interaction effects across factors on species' fitness related responses [119]. In addition to interactive effects of physical factors, biotic factors such as parasitism or chemical ecology of various organisms in an interactive multitrophic system may be affected resulting in distortions in predator-prey relationships. In such a case, the fate of some species populations in multitrophic systems will not be directly determined by the changes in climate on its population but by a species that is high or low in their food chain. Hence, wherever possible, experimental protocols that inform predictive models for changing climates should incorporate tests of other species, which might be of importance in the agro-ecosystems.

The ability of organisms to mount physiological responses to variation in temperature at different time-scales may be an important component of insect/natural enemy persistence and thus efficacy of biological control under climate change scenarios [80,110,111]. From a theoretical standpoint, rapid evolution of thermal tolerance traits/phenotypes and their plasticity has been predicted [80,90]. Some studies indicated that if plasticity has an additive genetic basis, plasticity levels might evolve and likely contribute to evolutionary adaptation [90]. Phenotypic plasticity may buffer organisms upon introduction to novel and thermally unfavorable environments [92] and thus ensure survival when facing climatic stress [91]. However, current experimental protocols and crop protection specialists are ignoring the role of evolutionary processes in designing ways to protect and even improve biodiversity under global climate change [120-122]. We therefore propose that biological insect pest management programs using natural enemies should aim at developing resilient agro-ecosystems that maintain species' and populations' evolutionary potential [123,124]. Pörtner and Farrell (2008) point out that this may be possible through improvement in genetic diversity and processes that encourage continuous in situ evolutionary adaptation [125]. In agriculture, use of evolutionary processes to manage biotic interactions can be of importance as discussed in [126]. Through the help of artificial selections in crops, parasitoids or any other biological agents used to control may even be enhanced to gain competitive advantage over the pests intended for control when facing a selection pressure such as heat or drought. Such an approach is not new in agriculture as it has already succeeded in crop breeding, domestication of animals and pesticide resistance management [122,126]. Hence if given the investment priority in research, some pests may be managed even better under changing climates.

Recent studies have proved that phenotypic plasticity can be used to enhance field performance of mass reared insects release for pest management $[82,83]$. We also argue that by manipulating thermal performance of mass-reared predators and parasitoids through acclimation, field performance in augmentative programs may at least be temporarily improved and hence improve pest management programs [86]. Similarly, [86] studies emphasize that pest management programs should incorporate valuable information acquired from studies of the evolutionary biology of thermal performance $[82,83,127]$. Likewise, this approach may be critical for improving efficacy of biological control programs in the face of climate change.

\subsection{Monitoring, Ecological Assessments and Ecosystem Management}

Apart from predictive models, regular monitoring and ecological assessments might be an important tool to accurately expose the impact of climate change on the distribution and abundance of pest and 
natural enemy populations. Whilst predictive models will be important in forecasting $[128,129]$, their predictive power is often limited by assumptions, which may lack ecological considerations [104,130,131]. Hence ecological assessments and monitoring will generate huge ecological data sets that may be overlooked by physiological studies or predictive models. Such ecological factors are likely to give more valuable information of how agents of biological control will interact under changing climates.

However, as the case with predictive models, assessments of various systems will require reliable ecological indicators in order to avoid making erroneous conclusions. These ecological indicators will serve as tools that portray the structure, function and composition of the ecosystems [132] or trends that will be happening over time [133] within and around the crops. Ecological indicators will therefore serve as early warning tools for detecting deficits in management strategies inflicted by climate change whilst also giving a database of various ecological transitions, which can be correlated to climate events. In turn, management strategies can be implemented earlier before extensive damage. However, as outlined by [132] use of ecological indicators can be problem if (i) the ecological indicators lack scientific integrity (ii) choice of indicators is confounded in management and (iii) the assessments are based on a small number of indicators. To counter this, concerted efforts between, scientists, farmers and policy makers should exist. Therefore, scientists should develop ecological assessment tools that are accurate but simplified to enable usage by a broad range of users. With adequate data collection from researchers, government agencies and farmers (at their local level) using well designed assessment tools, important conclusions can be drawn on the status of habitats, species composition and abundance in various regions.

Where parasitoid populations will be high but activity is reduced due to fragmented habitats, farmers can increase parasitoid attack on pests by use of companion cropping and plant indirect defense. Such is the case with the push-pull strategy used in the control of stemborers, which increases parasitisation of insect pests, by their parasitoids, through manipulation of the agro-ecosytem to lure parasitoids directly into the cropping system [50,51]. Augmentative strategies can also be used to boost parasitoid populations whilst using techniques such as acclimation to improve activity in variable environments $[82,83,86]$. Moreover, biological control can also be enhanced through feeding natural enemies with honey. This phenomenon has been shown to improve fecundity and longevity of hymenopteran parasitoids [52-54]. Hence identification for particular tactics and sometimes in combination will be important in tackling pests biologically under changing climates.

\section{Conclusion}

In conclusion, we propose that integrating physiology, population dynamics and climate mapping shows great promise for making robust predictions of the potential effects of global climate change on biodiversity [134]. Thus, to better elucidate the link between climate change, biodiversity and its impacts on biological control using natural enemies, a fruitful area of future studies would be in developing mechanistic physiological approaches (and ones that consider ecological factors) to understanding climate change effects on insect biology, biodiversity and population dynamics. Furthermore, there is significant evidence that species are evolving with climate change $[135,136]$. 
Hence future predictions of climate change effects on insect biodiversity should incorporate evolutionary potential $[123,124,137]$.

\section{Acknowledgements}

We are grateful to several anonymous referees for the critical and constructive comments on an earlier version of this manuscript. For funding and (or) institutional support, gratitude is expressed to BIUST funding to C.N., European Union [ADOPT project] and Carnegie Foundation (Wits-Carnegie Global Change Project) funding to F.C. P.M. was funded by SASRI.

\section{References}

1. Deutsch, C.A.; Tewksbury, J.J.; Huey, R.B.; Sheldon, K.S.; Ghalambor, C.K.; Haak, D.C.; Martin, P.R. Impacts of climate warming on terrestrial ectotherms across latitude. Proc. Natl. Acad. Sci.USA 2008, 105, 6668-6672.

2. Huey, R.B.; Deutsch, C.A.; Tewksbury, J.J.; Vitt, L.J.; Hertz, P.E.; Pérez, H.J.A.; Garland, T., Jr. Why tropical forest lizards are vulnerable to climate warming. Proc. R. Soc. London B 467 2009, 276, 1939-1948.

3. Dillon, M.E.; Wang, G.; Huey, R.B. Global metabolic impacts of recent climate warming. Nature 2010, 476, 704-707.

4. Parmesan, C.; Yohe, G. A globally coherent fingerprint of climate change impacts across natural systems. Nature 2003, 421, 37-42.

5. Colwell, R.K.; Brehm, G.; Cardelus, C.L.; Gilman, A.C.; Longino, J.T. Global warming, elevational range shifts, and lowland biotic attrition in the wet tropics. Science 2008, 322, $258-261$.

6. IPCC. Climate Change 2007: The Physical Science Basis. Contribution of Working Group I to the Fourth Assessment Report of the Intergovernmental Panel on Climate Change; Solomon, S., Qin, D., Manning, M., Chen, Z., Marquis, M., Averyt, K.B., Tignor, M., Miller, H.L., Eds.; Cambridge University Press: Cambridge, UK, 2007.

7. Easterling, D.R.; Meehl, G.A.; Parmesan, C.; Changnon, S.A.; Karl, T.R.; Mearns, L.O. Climate extremes: Observations, modelling, and impacts. Science 2000, 289, 2068-2074.

8. Frich, P.; Alexander, L.V.; Della-Marta, P.; Gleason, B.; Haylock, M.; Tank, A.M.K.; Peterson, T. Observed coherent changes in climatic extremes during the second half of the twentieth century. Clim. Res. 2002, 3, 193-212.

9. Battisti, A.; Stastny, M.; Buffo, E.; Larson, S. A rapid altitudinal range expansion in the pine processionary moth produced by the 2003 climatic anomaly. Glob. Change Biol. 2006, 12, $662-671$.

10. Tomozeiu, R.; Pavan, V.; Cacciamani, C.; Amici, M. Observed temperature changes in Emilia-Romagna: Mean values and extremes. Clim. Res. 2006, 31, 217-225.

11. Tebaldi, C.; Sansó, B. Joint projections of temperature and precipitation change from multiple climate models: A hierarchical Bayesian approach. J. R. Stat. Soc. 2009, 172, 83-106.

12. Im, E.S.; Jung, I.W.; Bae, D.H. The temporal and spatial structures of recent and future trends in extreme indices over Korea from a regional climate projection. Int. J. Clim. 2011, 31, 72-86. 
13. Kiritani, K. Predicting impacts of global warming on population dynamics and distribution of arthropods in Japan. Pop. Ecol. 2006, 48, 5-12.

14. Musolin, D.H. Insects in a warmer world: ecological, physiological and life history responses of true bugs (Heteroptera) to climate change. Glob. Change Biol. 2007, 13, 1565-1585.

15. Denlinger, D.L.; Lee, R.E. Low Temperature Biology of Insects; Cambridge University Press: Cambridge, UK, 2010.

16. Stevenson, R.D. The relative importance of behavioural and physiological adjustments controlling body temperature in terrestrial ectotherms. Am. Nat. 1985, 3, 362-386.

17. Huey, R.B.; Bennett, A.F. Physiological adjustments to fluctuating thermal environments: An ecological and evolutionary perspective. In Stress Proteins in Biology and Medicine; Cold Spring Harbor Laboratory Press: Cold Spring Harbor, NY, USA, 1990; pp. 37-59.

18. Chown, S.L.; Terblanche, J.S. Physiological diversity in insects: Ecological and evolutionary contexts. Adv. Insect Physiol. 2007, 33, 50-152.

19. Huey, R.B.; Pascual, M. Partial thermoregulatory compensation by a rapidly evolving invasive species along a latitudinal cline. Ecology 2009, 90, 1715-1720.

20. Chown, S.L.; Nicolson, S.W. Insect Physiological In Ecology: Mechanisms and Patterns; Oxford University Press: Oxford, UK, 2004.

21. Bowler, K. Acclimation, heat shock and hardening. J. Therm. Biol. 2005, 30, 125-130.

22. Lagerspetz, K.Y.H. What is thermal acclimation? J. Therm. Biol. 2006, 31, 332-336.

23. Huey, R.B.; Berrigan, D. Testing evolutionary hypothesis of acclimation. In Phenotypic and Evolutionary Adaptation to Temperatures; Johnston, I.A., Bennett, A.F., Eds.; Cambridge University Press: Cambridge, UK, 1996; pp. 205-237.

24. Hoffmann, A.A.; Sørensen, J.G.; Loeschcke, V. Adaptation of Drosophila to temperature extremes: Bringing together quantitative and molecular approaches. J. Therm. Biol. 2003, 28, $175-216$.

25. Fischer, K.; Eenhoorn, E.; Bot, A.N.M.; Brakefield, P.M.; Zwaan, B.J. Cooler butterflies lay larger eggs: Developmental plasticity versus acclimation. Proc. R. Soc. London B 2003, 270, 2051-2056.

26. Terblanche, J.S.; Chown, S.L. The relative contributions of developmental plasticity and adult acclimation to physiological variation in tsetse fly, Glossina pallidipes (Diptera: Glossinidae) J. Exp. Biol. 2006, 209, 1064-1073.

27. Martinat, P.J. The Role of Climatic Variation and Weather in Forest Insect Outbreaks. In Insect Outbreaks; Barbosa, P., Schultz, J.C., Eds.; Academic Press: San Diego, CA, USA, 1987; pp. 241-268.

28. Lafferty, K.D. The ecology of climate change and infectious diseases. Ecology 2009, 90, 888-900.

29. Nyamukondiwa, C.; Terblanche, J.S. Within-generation variation of critical thermal limits in adult Mediterranean and Natal fruit flies Ceratitis capitata and Ceratitis rosa: thermal history affects short term responses to temperature. Physiol. Entomol. 2010, 35, 255-264.

30. Marshall, K.E.; Sinclair, B.J. Repeated stress exposure results in a survival-reproduction trade-off in Drosophila melanogaster. Proc. R. Soc. London B 2010, 277, 963-969. 
31. Hoy, M.A. Parasitoids and Predators in Management of Arthropod Pests. In Introduction to Insect Pest Management; Metcalf, R.L., Luckman, W.H., Eds.; John Wiley Sons: New York, NY, USA, 1994.

32. Cammell, M.E.; Knight, J.D. Effects of climatic change on the population dynamics of crop pests. Adv. Ecol. Res. 1992, 22, 117-162.

33. Southwood, T.R.E.; Henderson, P.A. Ecological Methods; Blackwell Science: Oxford, UK, 2000.

34. Duale, A.H. Effect of temperature and relative humidity on the biology of the stem borer parasitoid Pediobius furvus (Gahan) (Hymenoptera: Eulophidae) for the management of stem borers. Environ. Entomol. 2005, 34, 1-5.

35. Sorribas, J.; van Baaren, J.; Garcia-Marí, F. Effects of climate on the introduction, distribution and biotic potential of parasitoids: Applications to biological control in California red scale. Biol. Control 2012, in press.

36. Liu, S.S.; Zhang, G.M.; Zhu, J. Influence of temperature variations on rate development in insects analysis of case studies from entomological literature. Ann. Entomol. Soc. Am. 1995, 88, 107-119.

37. Kalyebi, A.; Sithanantham, S.; Overholt, W.A.; Hassan, S.A.; Mueke, J.M. Parasitism, longevity and progeny production of six indigenous Kenyan trichogrammatid egg parasitoids (Hymenoptera: Trichogrammatidae) at different temperature and relative humidity regimes. Biocontrol. Sci. Technol. 2005, 15, 255-270.

38. Hance, T.; van Baaren, J.; Vernon, P.; Boivin, G. Impact of extreme temperatures on parasitoids in a climate change perspective. Ann. Rev. Entomol. 2007, 52, 107-126.

39. Porter, J.H.; Parry, M.L.; Carter, T.R. The potential effects of climate change on agricultural insect pests. Agric. Forest Meteorol. 1991, 57, 221-240.

40. Cannon, R.J.C. The implications of predicted climate change for insect pests in the UK, with emphasis on non-indigenous species. Global Change Biol. 1998, 4, 785-796.

41. Estay, S.A.; Lima, M.; Labra, F.A. Predicting insect pest status under climate change scenarios: combining experimental data and population dynamics modelling. J. Appl. Entomol. 2009, 133, 491-499.

42. Klok, C.J.; Chown, S.L. Critical thermal limits, temperature tolerance and water balance of a sub-Antarctic kelp fly, Paractora dreuxi (Diptera: Helcomyzidae). J. Insect Physiol. 2001, 47, 95-101.

43. Sasson, A. Food security in Africa: An urgent global challenge. Agric. Food Sec. 2012, doi:10.1186/2048-7010-1-2.

44. Lynch, S. Measuring progress in the transition to biologically-based IPM. In Proceedings of the OECD/FAO Workshop on Integrated Pest Management and Pesticide Risk Reduction, Neuchâtel, Switzerland, 28 June-2 July 1998.

45. Lockwood, J.A.; Ewen, A.B. Biological control of rangeland grasshoppers and locusts. In The Bionomics of Grasshoppers, Katydids and their Kin; Gangwere, S.K., Muralingan, M.C., Muralingan, M., Eds.; CABI International: Wallingford, UK, 1997; pp. 421-442.

46. Van Lenteren, J.C. The state of commercial augmentative biological control: Plenty of natural enemies, but a frustrating lack of uptake. BioControl 2011, 57, 1-20. 
47. Eilenberg, J.; Hajek, A.; Lomer, C. Suggestions for unifying the terminology in biological control. BioControl 2001, 46, 387-400.

48. Landis, D.A.; Wratten, S.D.; Gurr, G.M. Habitat management to conserve natural enemies of arthropod pests in agriculture. Ann. Rev. Entomol. 2000, 45, 175-201.

49. Jonsson, M.; Wratten, S.D.; Landis, D.A.; Gurr, G.M. Recent advances in conservation biological control of arthropods by arthropods. Biol. Control 2008, 45, 172-175.

50. Khan, Z.R.; James, D.G.; Midega, C.A.O.; Pickett, J.A. Chemical ecology and conservation biological control. Biol. Control 2008, 45, 210-224.

51. Cook, S.M.; Khan, Z.R.; Pickett, J.A. The use of 'push-pull' strategies in integrated pest management. Ann. Rev. Entomol. 2007, 52, 375-400.

52. Idris, A.B.; Grafius, E. Wildflowers as nectar sources for Diadegma insulare (Hymenoptera: Ichneumonidae), a parasitoid of diamondback moth, Plutella xylostella, (Lepidoptera: Plutellidae). Environ. Entomol. 1995, 24, 1726-1735.

53. Idris, A.B.; Grafius, E. Nectar-collecting behavior of Diadegma insulare (Hymenoptera: Ichneumonidae), a parasitoid of diamondback moth (Lepidoptera: Plutellidae) Environ. Entomol. 1997, 26, 114-120.

54. Johanowicz, D.; Mitchell, E.R. Effects of sweet alyssum flowers on the longevity of the parasitoid wasps Cotesia marginiventris (Hymenoptera: Braconidae) and Diadegma insulare (Hymenoptera: Ichneumonidae). Florida Entomol. 2000, 83, 41-47.

55. Talekar, N.S.; Shelton, A.M. Biology, ecology and management of diamondback moth. Ann. Rev. Entomol. 1993, 38, 275-302.

56. Perdikis, D.; Fantinou, A.; Lykouressis, D. Enhancing pest control in annual crops by conservation of predatory Heteroptera. Biol. Control 2011, 59, 13-21.

57. Gutierrez, A.P.; Ponti, L.; d'Oultremont, T.; Ellis, C.K. Climate change effects on poikilotherm tritrophic interactions. Clim. Change 2008, 87, S167-S192.

58. Colliera, T.; van Steenwyk, R. A critical evaluation of augmentative biological control. Biol. Control 2004, 31, 245-256.

59. Lomer, C.J.; Bateman, R.P.; Johnson, D.L.; Langewald, J.; Thomas, M. Biological control of locusts and grasshoppers. Ann. Rev. Entomol. 2001, 46, 667-702.

60. Macedo, N. Método de criação do parasitóide Cotesia flavipes (Cameron). In Controle, Biológico de Pragas: Produção massal e controle de qualidade; Bueno, V.H.P., Ed.; Editora UFLA: Lavras, Minas Gerais, Brazil, 2000; pp. 161-174.

61. Daane, K.M.; Yokota, G.Y.; Zheng, Y.; Hagen, K.S. Inundative release of common green lacewings (Neuroptera: Chrysopidae) to suppress Erythroneura variabilis and E. elegantula (Homoptera: Cicadellidae) in vineyards. Environ. Entomol. 1996, 25, 1224-1234.

62. Klein Koch, C.A. Proyectos de control biológico en curso en Ecuador. In M.C. Zapater El Control Biológico en América Latina; IOBC: Buenos Aires, Argentina, 1996; pp. 41-47.

63. Corrêa-Ferreira, B.S. Utilização do parasitóide de ovos Trissolcus basalis (Wollaston) no controle de percevejos da soja. In Circular Técnica 11; Embrapa-CNPSo: Londrina, Brazil, 1993 ; p. 40. 
64. Corrêa-Ferreira, B.S.; Moscardi, F. Biological control of soybean stink bugs by inoculative releases of Trissolcus basalis. Entomol. Exp. Appl. 2011, 79, 1-7.

65. Fargues, J.; Ouedraogo, A.; Goettel, M.S.; Lomer, C.J. Effect of temperature, humidity and inoculation method on susceptibility of Schistocerca gregaria to Metarhizium flavoviride. Biocontrol. Sci. Technol. 1997, 7, 345-356.

66. Jonsson, D.L.; Huang, H.C.; Harper, A.M. Mortality of grasshoppers (Orthoptera: Acrididae) inoculated with a Canadian isolate of the fungus Verticillium lecanii. J. Invertebr. Pathol. 1988, $52,335-342$.

67. Chown, S.L.; Sørenson, J.G.; Terblanche, J.S. Water loss in insects: An environmental change perspective. J. Insect Physiol. 2011, 57, 1070-1084.

68. Parmesan, C.; Ryrholm, N.; Stefanescu, C.; Hill, J.K.; Thomas, C.D.; Descimon, H.; Huntley, B.; Kaila, L.; Kullberg, J.; Tammaru, T.; et al. Pole ward shifts in geographical ranges of butterfly species associated with regional warming. Nature 1999, 399, 579-583.

69. Zachariassen, K.E. The water conserving physiological compromise of desert insects. Eur. J. Entomol. 1996, 93, 359-367.

70. Nair, U.S.; Lawton, R.O.; Welch, R.M.; Pielke, R.A., Sr. Impact of land use on Costa Rican tropical montane cloud forests: Sensitivity of cumulus cloud field characteristics to lowland deforestation. J. Geog. Res. 2003, doi:10.1029/2001JD001135.

71. Webb, T.J.; Woodward, F.J.; Hannah, L.; Gaston, K.J. Forest cover-rainfall relationships in a biodiversity hotspot: the Atlantic forest of Brazil. Ecol. Appl. 2005, 15, 1968-1983.

72. Markarieva, A.M.; Gorshkov, V.G. Biotic pump of atmospheric moisture as driver of the hydrological cycle on land. Hyd. Earth Sys. Sci. 2007, 11, 1013-1033.

73. Nicholls, C.I.; Parrella, M.; Altieri, M.A. Reducing the abundance of leafhoppers and thrips in a northern California organic vineyard through maintenance of full season floral diversity with summer cover crops. Agric. Forest Entomol. 2000, 2, 107-113.

74. Wilby, A.; Thomas, M.B. Are the ecological concepts of assembly and function of biodiversity useful frameworks for understanding natural pest control? Agric. Forest Entomol. 2002, 4, $237-243$.

75. Letourneau, D.K.; Armbrecht, I.; Rivera, B.S.; Lerma, J.M.; Carmona, E.J.; Daza, M.C.; Escobar, S.; Galindo, V.; Gutierrez, C.; Lopez, S.D.; et al. Does plant diversity benefit agroecosystems? A synthetic review. Ecol. Appl. 2011, 21, 9-21.

76. Dyer, J.M. Implications of habitat fragmentation on climate change-induced forest migration. Prof. Geog. 2005, 46, 449-459.

77. Opdam, P.; Wascher, D. Climate change meets habitat fragmentation: Linking landscape and biogeographical scale levels in research and conservation. Biol. Conserv. 2004, 117, 285-297.

78. Fahrig, L. Effects of habitat fragmentation on biodiversity. Annu. Rev. Ecol. Evol. S. 2003, 34, 487-515.

79. Cossins, A.; Bowler, K. Temperature Biology of Animals; Chapman and Hall: London, UK, 1987.

80. Angilletta, M.J. Thermal Adaptation. In A Theoretical and Empirical Synthesis; Oxford University Press: Oxford, UK, 2009. 
81. Basson, C.H.; Nyamukondiwa, C.; Terblanche, J.S. Fitness costs of rapid cold-hardening in Ceratitis capitata. Evolution 2011, 66, 296-304.

82. Kristensen, T.N.; Hoffmann, A.A.; Overgaard, J.; Sørensen, J.G.; Hallas, R.; Loeschcke, V. Costs and benefits of cold acclimation in field-released Drosophila. Proc. Natl. Acad. Sci. USA 2008, 105, 216-221.

83. Chidawanyika, F.; Terblanche, J.S. Costs and benefits of thermal acclimation for codling moth, Cydia pomonella (Lepidoptera: Tortricidae): implications for pest control and the sterile insect release programme. Evol. Appl. 2011, 4, 534-544.

84. Chidawanyika, F.; Terblanche, J.S. Rapid thermal responses and thermal tolerance in adult codling moth Cydia pomonella (Lepidoptera: Tortricidae). J. Insect Physiol. 2010, 57, $108-117$.

85. Bowler, K.; Terblanche, J.S. Insect thermal tolerance: What is the role of ontogeny, ageing and senescence? Biol. Rev. 2008, 83, 339-355.

86. Sørenson, J.G.; Addison, M.F.; Terblanche, J.S. Mass-rearing of insects for pest management: Challenges, synergies and advances from evolutionary physiology. Crop Prot. 2012, 38, 87-94.

87. Robinet, C.; Roques, A. Direct impacts of recent climate warming on insect populations. Integr. Zool. 2010, 2, 132-142.

88. Stacey, D. Climate and biological control in organic crops. Int. J. Pest Manage. 2003, 49, $205-214$.

89. Janzen, D.H. Why mountain passes are higher in tropics. Am. Nat. 1967, 101, 233-249.

90. Ghalambor, C.K.; Huey, R.B.; Martin, P.R.; Tewksbury, J.J.; Wang, G. Are mountain passes higher in the tropics? Janzen's hypothesis revisited. Integr Comp. Biol. 2007, 46, $5-17$.

91. Chown, S.L.; Slabber, S.; McGeoch, M.A.; Janion, C.; Leinaas, H.P. Phenotypic plasticity mediates climate change responses among invasive and indigenous arthropods. Proc. R. Soc. London. Ser. B 2007, 274, 2661-2667.

92. Nyamukondiwa, C.; Kleynhans, E.; Terblanche, J.S. Phenotypic plasticity of thermal tolerance contributes to the invasion potential of Mediterranean fruit flies (Ceratitis capitata). Ecol. Entomol. 2010, 35, 565-575.

93. Sithole, S.Z. Status and control of the Stem Borer, Chilo partellus Swinhoe (Lepidoptera: Pyralidae) in Southern Africa. Int. J. Trop. Sci. 1990, 11, 479-488.

94. Ong'amo, G.O.; Le Rü, B.P.; Dupas, S.; Moyal, P.; Calatayud, P.A.; Silvain, J.F. Distribution, pest status and agro-climatic preferences of lepidopteran stem borers of maize in Kenya. Ann. de la Société Entomol. de France 2006, 42, 171-177.

95. Thomson, L.J.; Macfadyen, S.; Hoffmann, A.A. Predicting the effects of climate change on natural enemies of agricultural pests. Biol. Control 2010, 52, 296-306.

96. Hilker, M.; Meiners, T. Early herbivore alert: insect eggs induce plant defence. J. Chem. Ecol. 2006, 32, 1379-1397.

97. Rodriguez-Saona, C.R.; Frost, C.J. New evidence for a multi-functional role of herbivore-induced plant volatiles in defense against herbivores. Plant Signaling Behav. 2010, 5, $58-60$.

98. Vickers, C.E.; Gershenzon, J.; Lerdau, M.T.; Loreto, F. A unified mechanism of action for volatile isoprenoids in plant abiotic stress. Nat. Chem. Biol. 2009, 5, 283-290. 
99. Gershenzon, J. Insects turn up their noses at sweating plants. Proc. Natl. Acad. Sci. USA 2008, $105,17211-172212$.

100. Loivamäki, M.; Mumm, R.; Dicke, M.; Schnitzler, J.P. Isoprene interferes with the attraction of bodyguards by herbaceous plants. Proc. Natl. Acad. Sci. USA 2008, 105, 17430-17435.

101. Laothawornkitkul, J.; Paul, N.D.; Vicker, C.E.; Possell, M.; Taylor, J.E.; Mullineaux, P.M.; Hewitti, C.N. Isoprene emissions influence herbivore feeding decisions. Plant Cell Environ. 2008, 31, 1410-1415.

102. Bruce, T.J.A.; Picket, J.A. Perception of volatile blends by herbivorous insects-Finding the right mix. Phytochemistry 2011, 72, 1605-1611.

103. Riveron, J.; Boto, T.; Alcorta, E. The effect of environmental temperature on olfactory perception in Drosophila melanogaster. J. Insect Physiol. 2009, 55, 943-951.

104. Pearson, R.G.; Dawson, T.P. Predicting the impacts of climate change on the distribution of species: are bioclimate envelope models useful? Global Ecol. Biogeogr. 2003, 12, 361-371.

105. Wiens, J.A.; Stralberg, D.; Jongsomjit, D.; Howell, C.A.; Snyder, M.A. Niches, models, and climate change: Assessing the assumptions and uncertainties. Proc. Natl. Acad. Sci. USA 2009, 106, 19729-19736.

106. Davis, A.J.; Jenkinson, L.S.; Lawton, J.H.; Shorrocks, B.; Wood, S. Making mistakes when predicting shifts in species range in response to global warming. Nature 1998, 391, 783-786.

107. Heikinnen, R.K.; Luoto, M.; Araujo, M.B.; Virkkala, R.; Thuiller, W.; Sykes, M.T. Methods and uncertainties in bioclimatic envelope modelling under climate change. Prog. Phys. Geog. 2006, 6, 1-27.

108. Mikkelsen, T.N.; Beier, C.; Jonasson, S.; Holmstrup, M.; Schmidt, I.K.; Ambus, P.; Pilegaard, K.; Michelsen, A.; Albert, K.; Andresen, L.C.; et al. Experimental design of multifactor climate change experiments with elevated $\mathrm{CO}_{2}$ warming and drought: the CLIMAITE project. Funct. Ecol. 2008, 22, 185-195.

109. Patori, G.M.; Foyer, C.H. Common components, networks, and pathways of cross-tolerance to stress. The central role of "Redox" and abscisic acid-mediated controls. Plant Physiol. 2002, 129, 460-468.

110. Hoffmann, A.A.; Chown, S.L.; Clusella-Trullas, S. Upper thermal limits in terrestrial ectotherms: How constrained are they? Funct. Ecol. 2012, in press.

111. Hanski, I.; Mononen, T. Eco-evolutionary dynamics of dispersal in spatially heterogeneous environments. Ecol. Lett. 2011, 14, 1025-1034.

112. Kellermann, V.; Heerwaarden, B.; Sgró, C.M.; Hoffmann, A.A. Fundamental evolutionary limits in ecological traits drive Drosophila species distributions. Science 2009, 325, $1244-1246$.

113. Hoffmann, A.A. Physiological climatic limits in Drosophila: patterns and implications. J. Exp. Biol. 2010, 213, 870-880.

114. Chown, S.L.; Hoffmann, A.A.; Kristensen, T.; Angilletta, M.; Strenseth, N. Adapting to climate change: a perspective from evolutionary physiology. Clim. Res. 2010, 43, 3-15.

115. Parmesan, C. Ecological and evolutionary responses to recent climate change. Ann. Rev. Ecol. Evol. Syst. 2006, 37, 637-669. 
116. Williams, S.E.; Shoo, L.P.; Isaac, J.L.; Hoffmann, A.A.; Langham, G. Towards and integrated framework for assessing the vulnerability of species to climate change. PLoS Biol. 2008, doi:10.1371/journal.pbio.0060325.

117. Lutterschmidt, W.I.; Hutchison, V.H. The critical thermal maximum: Data to support the onset of spasms as the definitive end point. Can. J. Zool. 1997, 75, 1553-1560.

118. Terblanche, J.S.; Hoffmann, A.A.; Mitchell, K.A.; Rako, L.; Le Roux, P.C.; Chown, S.L. Ecologically relevant measures of tolerance to potentially lethal temperatures. J. Exp. Biol. 2011, 214, 3713-3725.

119. Crozier, L.; Dwyer, G. Combining population-dynamic and ecophysiological models to predict climate-induced insect range shifts. Am. Nat. 2006, 167, 853-866.

120. Somero, G.N. The physiology of climate change: how potentials for acclimatisation and genetic adaptation will determine 'winners' and 'losers'. J. Exp. Biol. 2009, 213, 912-920.

121. Terblanche, J.S.; Nyamukondiwa, C.; Kleynhans, E. Thermal variability alters climatic stress resistance and plastic responses in a globally invasive pest, the Mediterranean fruit fly (Ceratitis capitata). Entomol. Exp. Appl. 2010, 137, 304-315.

122. Hendry, A.P.; Kinnison, M.T.; Heino, M.; Day, T.; Smith, T.B.; Fitt, G.; Bergstrom, C.T.; Oakeshott, J.; Jorgensen, P.S.; Zalucki, M.P.; et al. Evolutionary principles and their practical applications. Evol. Appl. 2011, 4, 159-183.

123. Hoffmann, A.A.; Sgrò, C.M. Climate change and evolutionary adaptation. Nature 2011, 470, 479-485.

124. Sgrò, C.M.; Lowe, A.J.; Hoffmann, A.A. Building evolutionary resilience for conserving biodiversity under climate change. Evol. Appl. 2010, 4, 326-337.

125. Pörtner, H.O.; Farrell, A.P. Physiology and climate change. Science 2008, 322, 690-692.

126. Thrall, P.H.; Oakeshott, J.G.; Fitt, G.; Southerton, S.; Burdon, J.J.; Sheppard, A.; Russell, R.J.; Zalucki, M.; Heino, M.; Denison, F.; et al. Evolution in agriculture: The application of evolutionary approaches to the management of biotic interactions in the agro-ecosystems. Evol. Appl. 2011, 4, 200-215.

127. Crandal, K. A multifacted approach to species conservation. Anim. Conserv. 2009, 12, 105-106.

128. Berry, P.M.; Dawson, T.P.; Harrison, P.A.; Pearson, R.G. Modelling potential impacts of climate change on the bioclimatic envelope of species in Britain and Ireland. Global Ecol. Biogeogr. 2002, 11, 453-462.

129. Pearson, R.G.; Dawson, T.P.; Berry, P.M.; Harrison, P.A. Species: A spatial evaluation of climate impact on the envelope of species. Ecol. Modell. 2002, 154, 289-300.

130. Guisan, A.; Thuiller, W. Predicting species distribution: offering more than simple habitat models. Ecol. Lett. 2005, 8, 993-1009.

131. Mustin, K.; Benton, T.G.; Dytham, C.; Travis, J.M.J. The dynamics of climate-induced range shifting; perspectives from simulation modeling. Oikos 2009, 118, 131-137.

132. Dale, V.H.; Suzanne, C.B. Challenges in the development and use of ecological indicators. Ecol. Indic. 2001, 1, 3-10.

133. Cairns, J.; McCormick, P.V.; Niederlehner, B.R. A proposed framework for developing indicators of ecosystem health. Hydrobiologia 1993, 236, 1-44. 
134. Hartley, S.; Krushelnycky, P.D.; Lester, P.J. Integrating physiology, population dynamics and climate to make multi-scale predictions for the spread of an invasive insect: The Argentine ant at Haleakala National Park, Hawaii. Ecography 2010, 33, 83-94.

135. Bradshaw, W.E.; Holzapfel, C.M. Evolutionary response to rapid climate change. Science 2006, 312, 1477-1478.

136. Hoffmann, A.A.; Daborn, P.J. Towards genetic markers in animal populations as biomonitors for human-induced environmental change. Ecol. Lett. 2007, 10, 63-76.

137. Kearney, M.; Porter, W.P.; Williams, C.; Ritchie, S.; Hoffmann, A.A. Integrating biophysical and evolutionary theory to predict climatic impacts on species' ranges: The dengue mosquito Aedes aegypti in Australia. Funct. Ecol. 2009, 23, 528-538.

(C) 2012 by the authors; licensee MDPI, Basel, Switzerland. This article is an open access article distributed under the terms and conditions of the Creative Commons Attribution license (http://creativecommons.org/licenses/by/3.0/). 